\title{
NUMERICAL SIMULATION OF HYDROLOGICAL AND HYDRODYNAMIC RESPONSES TO CHANNEL EROSION IN CHINA'S LARGEST FRESHWATER LAKE
}

\author{
LIANG, D. ${ }^{1}-$ LU, J. Z. ${ }^{1 *}-$ CHEN, X. L. ${ }^{1,2}-$ ZHANG, ${ }^{1}{ }^{1}$ \\ ${ }^{1}$ State Key Laboratory of Information Engineering in Surveying, Mapping and Remote Sensing, \\ Wuhan University, 129 Luoyu Road, Wuhan 430079, China \\ ${ }^{2}$ Key Laboratory of Poyang Lake Wetland and Watershed Research, Ministry of Education, \\ Jiangxi Normal University, Nanchang 330022, China \\ *Corresponding author \\ e-mail: lujzhong@whu.edu.cn; phone: +86-27-6877-8755
}

(Received $14^{\text {th }}$ Feb 2019; accepted $8^{\text {th }}$ Apr 2019)

\begin{abstract}
Topography determines the nature of hydrodynamic processes and its changes potentially affect the water quantity and quality. This study assessed the spatiotemporal impacts of topography changes on hydrological and hydrodynamic characteristics of China's largest freshwater lake, Poyang Lake. Results from simulation of different channel erosion intensities indicated that topography changes induced hydrological and hydrodynamic variations with spatiotemporal heterogeneity. Water levels in the lake decreased and the effect was enhanced with stronger erosion intensities. The decrease in water level was significant during the dry period, but negligible during the wet period. Water levels decreased by an average of $0.90-1.1 \mathrm{~m}$ in the northern channel during the dry period, and $0.27 \mathrm{~m}$ and $0.20 \mathrm{~m}$ in the central and eastern lakes during the rising and recession periods. The changing water level further affected the distribution of water with the effect of gathering water to the channel from nearby areas. Moreover, channel erosion altered the lake-river interactions. During the dry period, outflow discharges increased as the channel conveyance capacity increased by $25-136 \%$. In contrast, during the wet period, outflow discharges decreased as the inflow regulation volume increased by $3.8-8.2 \times 10^{8} \mathrm{~m}^{3}$. Particularly, backflow frequency and volume increased during the flooding period of the Yangtze River. In addition, the dry period in Poyang Lake was extended, and the frequency of low-water events increased significantly. This study demonstrated the spatiotemporal impacts of topographical changes on hydrodynamic processes in Poyang Lake, therefore providing a better understanding of variations in water regimes and lake-river interactions.
\end{abstract}

Keywords: topography changes, hydrological and hydrodynamic impacts, numeric model, ecohydrology, Poyang Lake

\section{Introduction}

Topography has a fundamental control on the flow of water in gravity-driven shallow waters. It has a strong influence on the hydrological and hydrodynamic characteristics of water systems, and is closely related to water quantity and quality (Oliveira et al., 2006; Rinaldi et al., 2008; Malhadas et al., 2009; Mosley, 2015). Changes in topography affect flow patterns and material transportation, and these variations, in turn, alter the topographic evolution. Erosion and sedimentation processes occur frequently through interaction between water and suspended matters (Yang et al., 2007). As water usually contains suspended matters, such as mud, sand, salt, and floating algae, suspended particles contained in the flow can be deposited and attach to the surface of the bed or the bank of the watercourse. Thus depositional processes may increase the bottom surface and make the cross section of the waterway narrower. Conversely, the erosion process entrains particles from the bottom surface into the water and scours the bed and 
sidewalls, making the watercourse deeper and wider. Under the combined effects of deposition and erosion, underwater topography usually changes slowly. Therefore, topography is regarded to be stable over short timescales and deformation is often neglected in studies of hydrological and hydrodynamic processes. However, disasters such as landslides, earthquakes, and debris flows, as well as human activities, such as dredging, lake infilling, and dam construction, can change topography in a short amount of time. The bottom may be raised or lowered, or the watercourse may be broken up, blocked, or diverted. Thus the spatial characteristics may change significantly. As an influential factor to hydrodynamic processes, topography changes have a substantial impact on water flow, water distribution, and material transportation, affecting the availability of water consumption for living organisms, agriculture and industry, as well as for ecological processes.

Poyang Lake, the largest freshwater lake in China, is one of the few existing lakes connected to the Yangtze River. The lake has a complex underwater topography (Feng et al., 2011) influenced by erosion and deposition processes. Moreover, human activities in Poyang Lake, including lake reclamation, reservoir construction and sand mining, induced significant changes (Min, 2000; Lai et al., 2014). Studies have indicated that active sand dredging in Poyang Lake after the enactment of a sand mining ban in Yangtze River in 2001 have altered the lake to an erosional system (Lai et al., 2014; Li et al., 2014). Monitoring the sand-dredging activities in Poyang Lake through remote sensing imagery was used to estimate the location and extent of decrease in elevation (Leeuw et al., 2010; Li et al., 2014). Further comparison of DEMs extracted from remote sensing images and in situ bathymetry measurements showed that the outflow channel was deeper and wider than before (Cui et al., 2009; Feng et al.,. 2011; Lai et al., 2014; Qi et al., 2014; Wu et al., 2015; Yao et al., 2018). Using the bathymetry data acquired in 1998 and 2010, Wu et al. (2015) found that the bottom elevation decreased $3.7 \mathrm{~m}$ on average in the outflow channel of the lake and $2 \mathrm{~m}$ on average in the inflow channel of the western branch of Ganjiang from 1998 to 2010, respectively. These studies traced topography changes using multiple methods, and provided the foundation for further studies on the impact of topography changes on hydrodynamic processes in the lake.

In recent years, serious problems, such as severe drought, the earlier arrival of the dry period, and wetland recession, have attracted wide attentions. Topographical changes across Poyang Lake are considered a critical element impacting the hydrology and hydrodynamic characteristics of the lake. Empirical analysis based on observations were used to show the correlation between channel deformation and hydrological and hydrodynamic fluctuations. Gao et al. (2014) analyzed and examined water discharges and sediment load data of Poyang Lake. The study deduced that a deepened channel increased the outflow and sediment flowing from the lake. Moreover, the river-lake interaction was potentially altered by channel morphological changes. Lai et al. (2014) estimated the lake conveyance capacity using outflow discharge and water level observations and deduced that the discharge ability of the lake increased during the dry period. The study demonstrated that the decreasing channel elevation influenced the abnormal low water levels during the winter dry season. These studies, based on observations and empirical analysis, suggested a link between channel erosion and hydrological and hydrodynamic changes in Poyang Lake. However, the impact of channel erosion cannot be fully explained by physical processes. Yao et al. (2018) quantified the impact of bathymetric changes on the lake's water level using a 
hydrodynamic model. The influence on hydrological and hydrodynamic characteristics, such as water distribution and lake-river interaction, were not considered. It is necessary to assess the spatiotemporal influence of channel erosion through a physically based hydrodynamic model to better understand the hydrological, hydrodynamic, and ecological changes in the lake.

In this study, we aim to assess the spatiotemporal hydrological and hydrodynamic responses to channel erosion in Poyang Lake using a numeric method. A hydrodynamic model is constructed to reveal the flow characteristics. The established model is used for simulating the streamflow processes with different channel erosion intensities. The spatiotemporal impacts of topography changes on hydrological and hydrodynamic characteristics, including the lake water level, water distribution, lake-river interaction, and the wet-dry characteristics, are assessed. This study shows the spatiotemporal impact of topography change on water regime fluctuations and water quality changes in a shallow water system. The simulation supports analysis of spatiotemporal variations of hydrological and hydrodynamic characteristics, which will assist analysis of the driving forces related to water shortage problems, as well as terrestrial and aquatic environment dynamics. Therefore, more effective measures can be taken to solve problems in water supply shortages and water pollution.

\section{Materials and methods}

\section{Study area and dataset}

Poyang Lake is located in the middle section of the Yangtze River. The lake has a complex topography with shallow floodplain areas separated and alternating with deeper channels. The elevation of the lake bottom decreases markedly from south to north. The local annual precipitation around Poyang Lake fluctuates by approximately $1620 \mathrm{~mm}$, and it changes dramatically affected by the subtropical humid monsoon climate. Water regimes and hydrodynamic characteristics of Poyang Lake show spatiotemporal heterogeneity. In the wet season period, usually from April to September, water level at Duchang (the representative gauge in Poyang Lake) rises to more than $12.8 \mathrm{~m}$ (Min and Zhan, 2012) and the inundation area expands to more than $3000 \mathrm{~km}^{2}$ (Feng et al., 2012a), covering most of the lake extent. In the dry period, usually from October to March, the inundation area can shrink to less than $1000 \mathrm{~km}^{2}$, and the lake assumes a river-like shape. The difference in water surface elevation from south to north can be more than $5 \mathrm{~m}$ in the dry period, whereas there is little difference during the wet period. Consequently, the flow velocity in the dry period is much faster than in the wet period. As a throughput type lake, Poyang Lake usually regulates water from five main rivers in the catchment, including the Xiushui, Ganjiang, Fuhe, Xinjiang, and Raohe (Fig. 1), and drains into the Yangtze River through the Hukou outlet. During flooding periods however, high water level in the Yangtze River, usually from July to September, may lead to backflow into the lake as well. The lake-river interactions exert a profound impact on the hydrological and hydrodynamic characteristics of Poyang Lake.

Three types of data were used in this study, including in situ measurements and products of the bottom elevation, daily water level and discharge data from the gauge stations, and satellite remote sensing images. Underwater terrain data was acquired in 1998 by the Changjiang Water Resources Commission of China. Changes in channel elevation between 1998 and 2010 were provided by the Jiangxi Administration of 
Surveying, Mapping and Geoinformation (http://www.jxcehui.gov.cn). The bottom elevation data was processed to generate bathymetry for our numeric model. Time series of daily station discharge and water level data over the study period (January 1, 2001 to December 31, 2002) were collected from the Jiangxi Bureau Hydrology Department (http://www.jxsw.cn/). Upstream discharge data were collected from seven gauging stations (Qiujin, Wanjiabu, Waizhou, Lijiadu, Meigang, Hushan, and Dufengkeng) on the five main rivers in the catchment. Among them, Qiujin and Wanjiabu measure discharge from the Xiushui, Waizhou for Ganjiang, Lijiadu for Fuhe, Meigang for Xinjiang, and Hushan and Dufengkeng for Raohe (Fig. 1). Downstream discharge data at Hukou, which monitors the lake-river interaction, was collected. Water level data from six hydrological stations (Hukou, Xingzi, Duchang, Tangyin, Longkou, Kangshan) across Poyang Lake were collected to document the water regime of the lake. Besides, the 40-year (from 1970 to 2009) time series daily water level data at Duchang and Hukou were collected to analyze the water regime changes. A Landsat ETM+ image acquired on August 12, 2010 when a large flood occurred in Poyang Lake, was obtained from the USGS (https://glovis.usgs.gov/) to extract the extent of the water boundary.

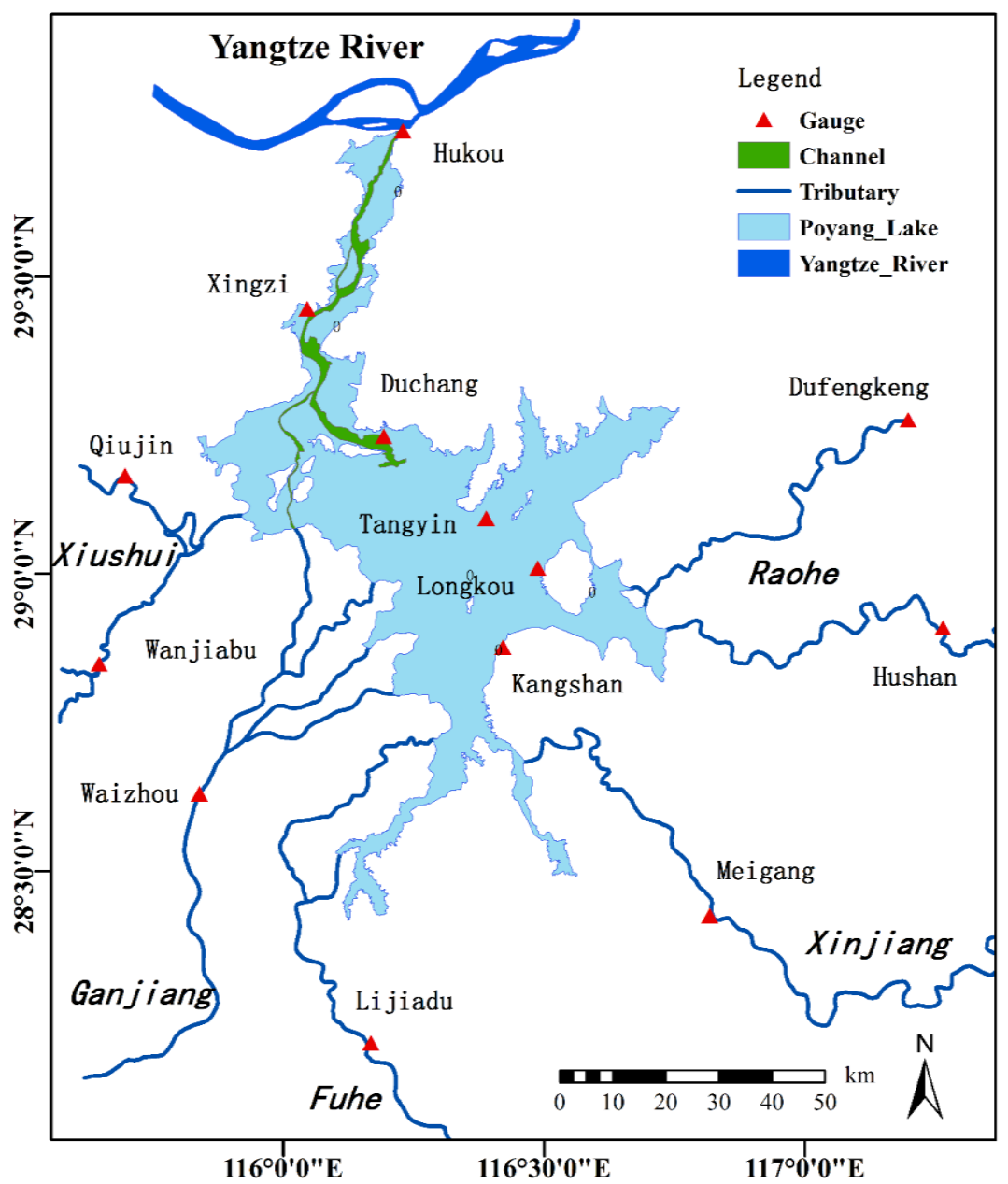

Figure 1. Location of Poyang Lake and gauging stations. The lake inflow sources consist of five main tributaries: Xiushui, Ganjiang, Fuhe, Xinjiang, and Raohe. Water flow into the lake and run south-to-north through the channel into the Yangtze River at Hukou. Gauging stations on the tributaries and hydrological stations in the lake are marked as red triangles 


\section{Methodology}

\section{Hydrodynamic model of Poyang Lake}

In this study, a hydrodynamic model of Poyang Lake was established based on Delft3D-Flow, which is a module of the open source software Deltares (Delft Hydraulics, 2014). The software was developed to investigate hydrodynamics, sediment transport and water quality for fluvial, estuarine and coastal environments. As vertical currents could be neglected in Poyang Lake (Li et al., 2014; Zhang et al., 2015), a 2D free-surface model was constructed. The numerical program has been widely used to reveal hydrodynamic processes and transport phenomena in shallow waters.

Delft-Flow calculates multidimensional hydrodynamics based on the Navier Stokes equations, which consist of the continuity equation and the momentum equations. In an orthogonal coordinate system, the depth-averaged continuity and momentum equations are described as follows (Eqs. 1-3):

Continuity equation:

$$
\frac{\partial \varsigma}{\partial t}+\frac{1}{\sqrt{G_{\xi \xi} G_{\eta \eta}}} \frac{\partial\left[(d+\varsigma) U \sqrt{G_{\eta \eta}}\right]}{\partial \xi}+\frac{1}{\sqrt{G_{\xi \xi} G_{\eta \eta}}} \frac{\partial\left[(d+\varsigma) V \sqrt{G_{\eta \eta}}\right]}{\partial \eta}=(d+\varsigma) q
$$

Momentum equations:

$$
\begin{aligned}
& \frac{\partial u}{\partial t}+\frac{u}{\sqrt{G_{\xi \xi}}} \frac{\partial u}{\partial \xi}+\frac{v}{\sqrt{G_{\eta \eta}}} \frac{\partial u}{\partial \eta}+\frac{\omega}{d+\varsigma} \frac{\partial u}{\partial \sigma}-\frac{v^{2}}{\sqrt{G_{\xi \xi} G_{\eta \eta}}} \frac{\partial \sqrt{G_{\eta \eta}}}{\partial \xi}+\frac{u v}{\sqrt{G_{\xi \xi} G_{\eta \eta}}} \frac{\partial \sqrt{G_{\xi \xi}}}{\partial \eta}-f v \\
& =-\frac{1}{\rho \sqrt{G_{\xi \xi}}} P_{\xi}+F_{\xi}+\frac{1}{(d+\varsigma)^{2}} \frac{\partial}{\partial \sigma}\left(v_{v} \frac{\partial u}{\partial \sigma}\right) \\
& \frac{\partial v}{\partial t}+\frac{u}{\sqrt{G_{\xi \xi}}} \frac{\partial v}{\partial \xi}+\frac{v}{\sqrt{G_{\eta \eta}}} \frac{\partial v}{\partial \eta}+\frac{\omega}{d+\varsigma} \frac{\partial v}{\partial \sigma}-\frac{u^{2}}{\sqrt{G_{\xi \xi} G_{\eta \eta}}} \frac{\partial \sqrt{G_{\xi \xi}}}{\partial \eta}+\frac{u v}{\sqrt{G_{\xi \xi} G_{\eta \eta}}} \frac{\partial \sqrt{G_{\eta \eta}}}{\partial \xi}+f u \\
& =-\frac{1}{\rho \sqrt{G_{\eta \eta}}} P_{\eta}+F_{\eta}+\frac{1}{(d+\varsigma)^{2}} \frac{\partial}{\partial \sigma}\left(v_{v} \frac{\partial v}{\partial \sigma}\right)
\end{aligned}
$$

where $\xi, \eta$ are the horizontal curvilinear coordinates and $\sigma$ is the scaled vertical coordinate; $\mathrm{G}_{\xi \xi}$ and $\mathrm{G}_{\eta \eta}$ are the coefficients to transform curvilinear to rectangular coordinates; $\zeta$ represents water level above the reference plane, and $d$ represents water depth below the reference plane; $(\mathrm{u}, \mathrm{v})$ represent the flow velocity and $(\mathrm{U}, \mathrm{V})$ represent the depth-averaged flow velocity of the $\xi$ - and $\eta$-direction, respectively; q represents the contributions of source and sink terms per unit area; $\omega$ represents the vertical velocity in the adapting $\sigma$-coordinate; $v_{\mathrm{v}}$ represent the vertical eddy viscosity coefficient; $f$ represents the Coriolis coefficient; $P_{\xi}$ and $P_{\eta}$ represent the pressure gradients; $F_{\xi}$ and $F_{\eta}$ represent the unbalance of horizontal Reynold's stresses; $\rho$ represents the density of water.

The set of partial differential equations were solved by an implicit finite difference method on a staggered grid. To get a good solution from the hydrodynamic model, we should specified a set of model inputs, which can be divided into four data groups 
including model domain and time parameters, boundary conditions, initial conditions, and physical parameters. Model domain is usually defined by the computational grid and bathymetry. The time parameters contain the simulation runtime and computation steps. In the numeric model, the inflow and outflow boundary conditions are often used to restrict the computation, and the initial hydrodynamic state of the computation domain are used to launch the model. Physical parameters contain physical constants, such as water density, and calibration factors, such as bottom roughness.

To obtain the maximum water boundary for model calculation, a Landsat image acquired on August 12, 2010 was employed when a large flood occurred and the entire lake was covered by water (Zhang et al., 2015). Disconnected segments separated by islands and artificial structures were removed. Rectangle model grids were generated based on the maximum water boundary with a resolution of $300 \mathrm{~m}$. The bottom topography data was processed to fit the coordinate system in Delft3D and interpolated into the model grid points. The run time of the simulation extended from January 1, 2001 to December 31, 2002, covering both complete wet and dry periods. The computation time step was set as 1 minute to meet the Courant-Friedrichs-Lewy (CFL) condition, which is related to model stability and accuracy (Delft Hydraulics, 2014). To simulate the dramatically and rapidly changing inundation extent in Poyang Lake, a drying and flooding algorithm was used in our study. Grids were removed from the computation domain when grids became dry as the water fell. Conversely, grids were added to the computation domain when grids became wet as the water rose.

Boundary conditions at the inflow and outflow were specified to restrict the computation. The upper open boundary was prescribed as the daily inflow discharges of Poyang Lake. As there is an ungauged area of $19,867 \mathrm{~km}^{2}$ between the gauging stations of the five main inflow rivers and Poyang Lake (Zhang et al., 2014; Li et al., 2014; Zhang et al., 2017), daily total inflow discharges were calculated from the gauged discharges by using a simple water balance model put forward by Zhang et al. (2014). The lower open boundary of the model was prescribed as the daily water level at Hukou. Initial conditions were obtained by interpolating the measured water levels from the gauge stations in Poyang Lake.

After establishing the hydrodynamic model, the calibration and validation process were performed to make the model suitable for use. In this study, initial parameter values of the constructed hydrodynamic model were defined based on literature values (Zhang et al., 2015; Li et al., 2016; Qi et al., 2016) and recommended values in the Delft3D user manual (Delft Hydraulics, 2014). A trial-and-error method was used to adjust the critical parameters (Zhang et al., 2015), including bottom roughness, eddy viscosity, and threshold depth for drying and flooding, to optimal values by comparing simulated results with station observations. Daily water levels at the five hydrological stations in the lake (Xingzi, Duchang, Tangyin, Longkou, and Kangshan) and discharge data at Hukou station in 2001 was employed for model calibration and data in 2002 was used for model validation. Statistical indices, including the coefficient of determination $\left(\mathrm{R}^{2}\right)$, the Nash-Sutcliffe Efficiency coefficient (NSE), and percent bias (PBIAS), were calculated for evaluating the performance of the model (Moriasi et al., 2007).

\section{Channel erosion simulation}

To evaluate the impact of bottom deformation on hydrodynamic characteristics of rivers and lakes, the deformation area and intensity should be estimated firstly. Figure $2 a$ shows the bottom elevation of Poyang Lake in 1998 and Figure $2 b$ shows the 
elevation change from 1998 to 2010. The remarkable decrease in channel elevation was the main feature of topographical changes in Poyang Lake during this period. The bottom elevation in the main channel and the inflow channel of the western branch of Ganjiang (as shown in Fig. 1) decreased by an average of $4.0 \mathrm{~m}$ and $2.1 \mathrm{~m}$, respectively. In our experiment, channel erosion in these areas was considered. Four scenarios, including slight, moderate, serious and severe intensity, were set to simulate different intensities of channel erosion in the lake. The severe channel erosion was set as the loss in channel bottom elevation from 1998 to 2010 by average of $4.0 \mathrm{~m}$. The bottom elevation after slight, moderate and serious intensity of channel were obtained by interpolation, with an average of $1.0 \mathrm{~m}, 2.0 \mathrm{~m}$, and $3.0 \mathrm{~m}$ decrease in the main channel. Bottom topography was processed and re-interpolated to hydrodynamic model grid points. In order to distinguish the impact of channel erosion on the hydrological and hydrodynamic characteristics in Poyang Lake, the same model configurations, except for bathymetry data, were used for simulations in all four scenarios.
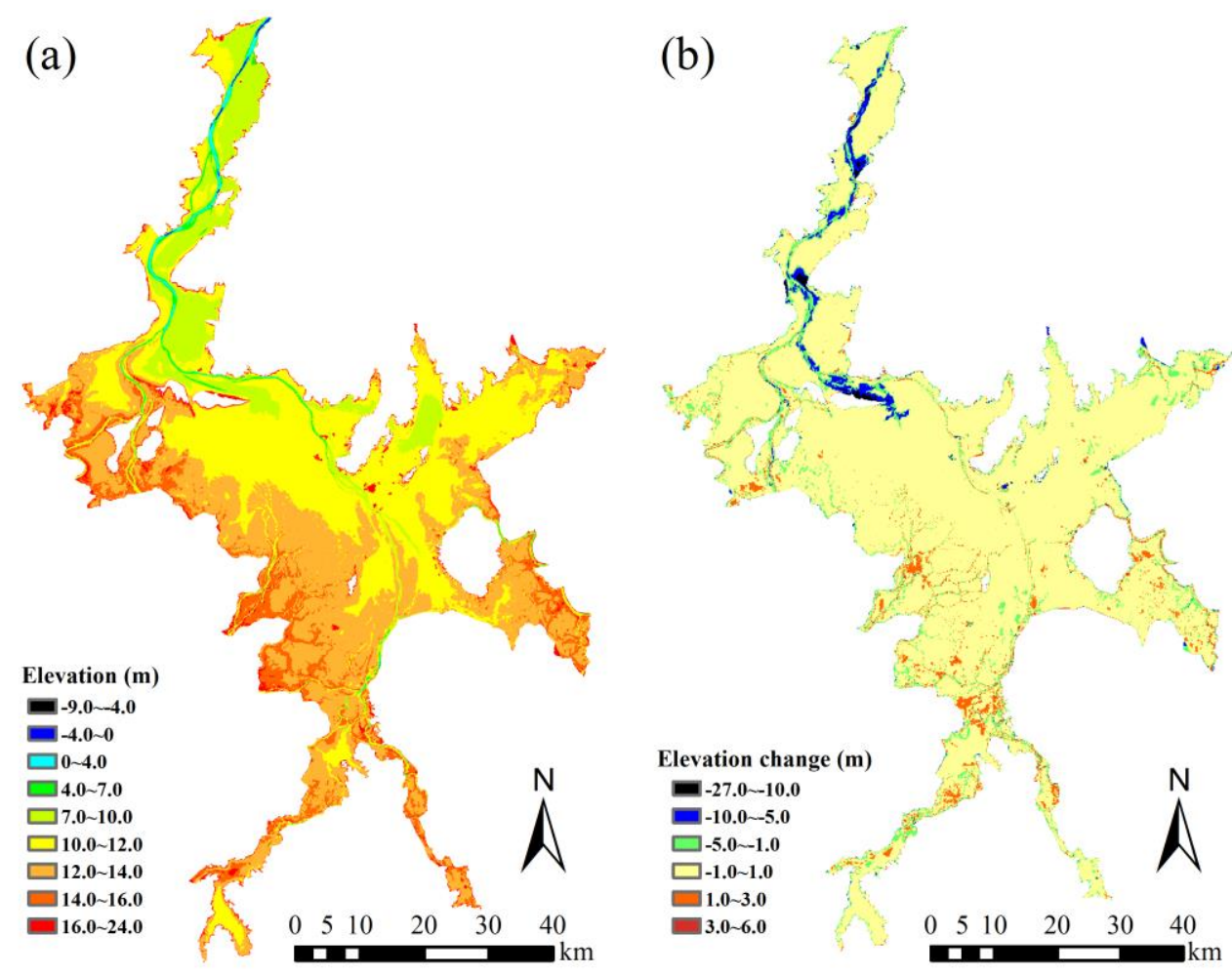

Figure 2. $\boldsymbol{a}$ The bottom elevation of Poyang Lake acquired in 1998. $\boldsymbol{b}$ Topography changes from 1998 to 2010

\section{Results}

\section{Observed changes of water regime}

Figure 3 shows the variations of the averages of daily water levels from 2000 to 2009 at Duchang and Hukou, compared to the 40-year (from 1970 to 2009) average conditions. Water levels in Poyang Lake were generally lower during the 2000s. Compared to the 40-year average, mean water level during the 2000s decreased approximately $0.68 \mathrm{~m}$ and $0.55 \mathrm{~m}$ at Duchang and Hukou, respectively. And the dry 
period in the lake during the 2000s became approximately 40 -day longer. The results indicated that Poyang Lake experienced a more severe dry condition in the 2000s.

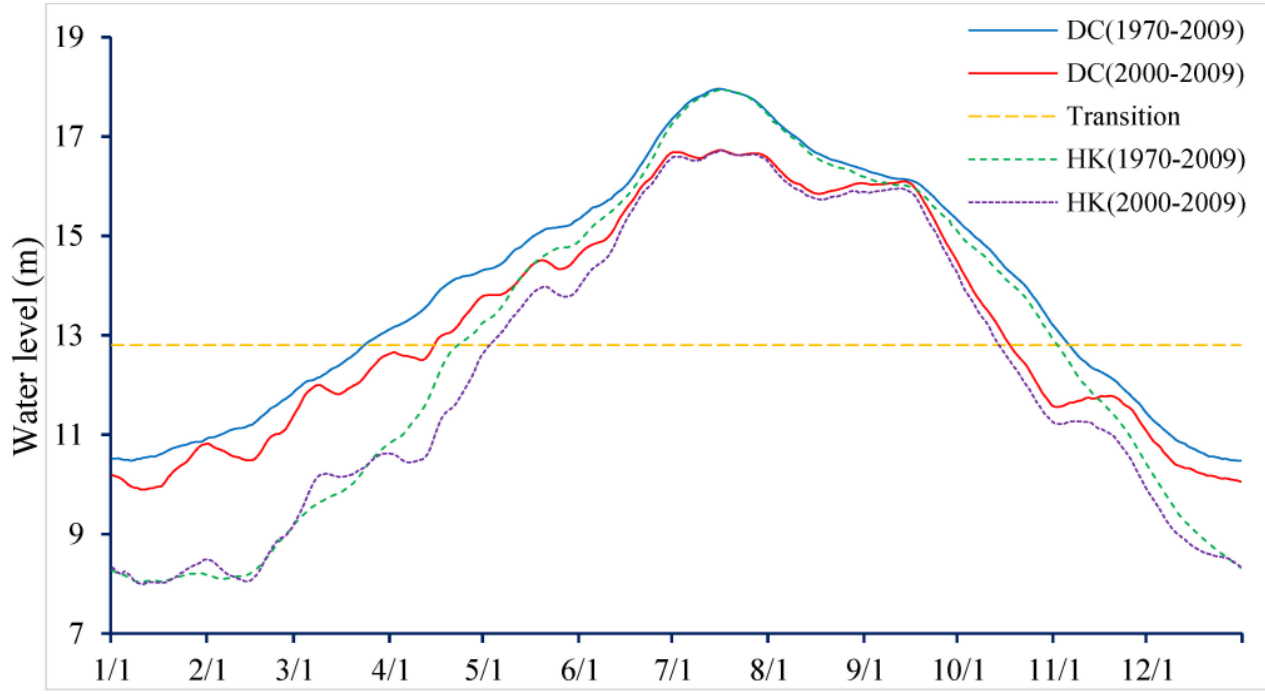

Figure 3. Daily mean water level variations of the 2000s compared to the averages from 1970 to 2009 at Duchang (DC) and Hukou (HK). The "Transition" water level represents the transition water level of the wet and dry periods at Duchang in Poyang Lake

\section{Hydrodynamic model evaluation}

Parameters of the hydrodynamic model were calibrated by comparing the simulated water levels and discharges to the measurements in 2001. After many tests by repeatedly refining the critical parameters, the Manning roughness was set to be $0.020 \mathrm{~s} / \mathrm{m}^{1 / 3}$ for the channel and $0.030 \mathrm{~s} / \mathrm{m}^{1 / 3}$ for floodplain area according to the terrain features. Eddy viscosity was set to $1 \mathrm{~m}^{2} / \mathrm{s}$ and the threshold depth for drying and flooding was set to $0.10 \mathrm{~m}$. The calibrated model was validated based on a comparison between simulation results and observations in 2002. Statistic indices were calculated to evaluate model performance (Table 1). Simulated water levels and outflow discharges were compared to station observations over the calibration and validation period, as shown in Figure 4. Results show that the hydrodynamic model is capable of capturing the dynamic changes of Poyang Lake. Simulated water levels are consistent with observations from the five hydrological stations (Xingzi, Duchang, Tangyin, Longkou and Kangshan) from north to south of the lake in both the calibration and validation periods. The $\mathrm{R}^{2}$ and NSE of Xingzi, Duchang, Tangyin, Longkou and Kangshan gauging stations are all higher than 0.95 and 0.93 , respectively, which indicate that most of the variance in the measured data could be explained by the model and the simulated results fit the observations well. The PBIAS values vary from $-0.72 \%$ to $0.76 \%$, which suggests no significant overestimation or underestimation in the model. In particular, the significant overestimation of water levels during the dry period caused by bathymetry errors (Lai et al., 2011) was eliminated. The results indicate that the hydrodynamic model is able to reproduce the rapid water level changes over wet and dry periods, as well as the remarkable spatial variation. The associated $\mathrm{R}^{2}$ and NSE of simulated discharge at Hukou station are all larger than 0.9 and the PBIAS during calibration and validation are $5.78 \%$ and $1.18 \%$ respectively, which suggests an 
acceptable level of accuracy for the discharge simulation. Generally, the calibrated and validated hydrodynamic model employed in this study has the capability to simulate the hydrological and hydrodynamic characteristics of Poyang Lake. Thus, it provides the possibility of reproducing and predicting of hydrodynamics of the lake.

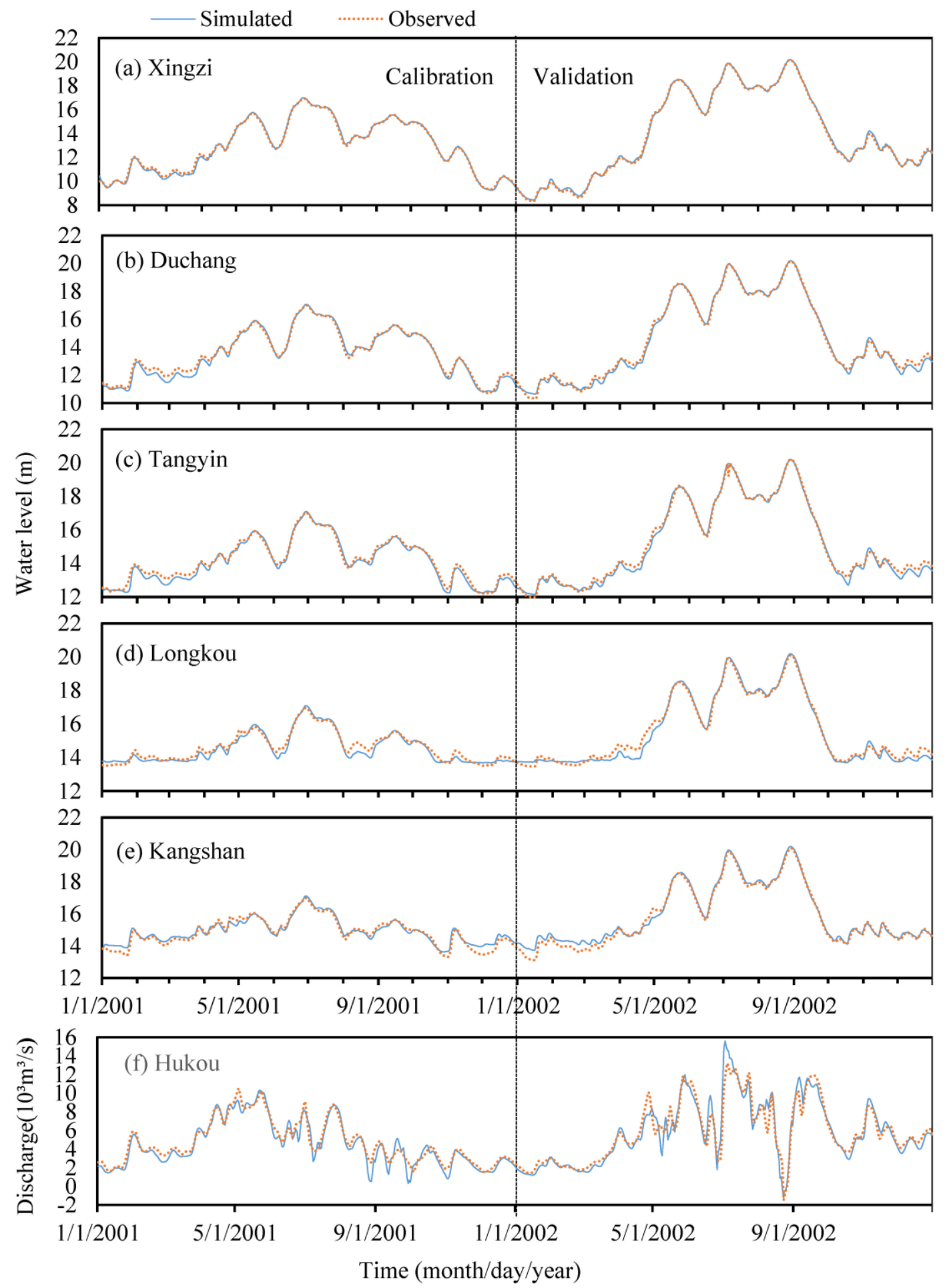

Figure 4. Comparison of simulated (solid line) water levels at $\boldsymbol{a}$ Xingzi, $\boldsymbol{b}$ Duchang, $\boldsymbol{c}$ Tangyin, $\boldsymbol{d}$ Longkou, $\boldsymbol{e}$ Kangshan and outflow discharges at $\boldsymbol{f}$ Hukou and hydrological station measurements (dotted line) in Poyang Lake during the model calibration and validation periods 
Table 1. Quantitative assessment of hydrodynamic model performance for daily water level and discharge during the calibration and validation periods

\begin{tabular}{|c|c|c|c|c|c|c|c|}
\hline & \multirow{2}{*}{ Indices } & \multicolumn{5}{|c|}{ Water level } & \multirow{2}{*}{$\begin{array}{c}\text { Discharge } \\
\text { Hukou }\end{array}$} \\
\hline & & Xingzi & Duchang & Tangyin & Longkou & Kangshan & \\
\hline \multirow{3}{*}{$\begin{array}{l}\text { Calibration } \\
\text { period (2001) }\end{array}$} & $\mathrm{R}^{2}$ & 0.998 & 0.993 & 0.989 & 0.954 & 0.952 & 0.936 \\
\hline & NSE & 0.997 & 0.986 & 0.977 & 0.936 & 0.936 & 0.909 \\
\hline & PBIAS & $0.16 \%$ & $0.68 \%$ & $0.76 \%$ & $0.65 \%$ & $-0.44 \%$ & $5.78 \%$ \\
\hline \multirow{3}{*}{$\begin{array}{l}\text { Validation } \\
\text { period (2002) }\end{array}$} & $\mathrm{R}^{2}$ & 0.999 & 0.997 & 0.996 & 0.988 & 0.989 & 0.922 \\
\hline & NSE & 0.999 & 0.996 & 0.994 & 0.984 & 0.985 & 0.910 \\
\hline & PBIAS & $-0.27 \%$ & $0.40 \%$ & $0.52 \%$ & $0.51 \%$ & $-0.72 \%$ & $1.18 \%$ \\
\hline
\end{tabular}

\section{Water levels influenced by channel erosion}

The simulated daily water levels under different channel erosion intensities at the five stations were compared to the conditions before channel erosion. Figure 5 indicates that water levels in Poyang Lake became lower after channel erosion. An increased reduction in water levels occurred at the five stations as the channel became deeper. However, the impact of channel erosion on water levels is spatially and temporally heterogeneous. The extent of water level decline varies over time and space.

Table 2 shows the changes of mean water level at the five gauging stations under different channel erosion intensities. Mean water level reductions during the simulation period all increased with downcutting depth, nonlinearly. Water levels at Duchang station decreased the most after channel erosion, followed by Xingzi, Tangyin, Longkou, and Kangshan. Under severe channel erosion conditions, mean water levels at Duchang and Xingzi decreased by $0.551 \mathrm{~m}$ and $0.422 \mathrm{~m}$, respectively. Meanwhile, mean water level decreased by approximately $0.1 \mathrm{~m}$ at Tangyin and less than $0.1 \mathrm{~m}$ at Longkou and Kangshan.

Table 2. Changes of mean water level (unit: $m$ ) under different channel erosion intensities (slight, moderate, serious, severe intensity) compared to the original scenario at five hydrological stations in Poyang Lake during the simulation period

\begin{tabular}{c|c|c|c|c|c}
\hline & Xingzi & Duchang & Tangyin & Longkou & Kangshan \\
\hline Slight & -0.183 & -0.229 & -0.049 & -0.025 & -0.021 \\
Moderate & -0.301 & -0.401 & -0.075 & -0.040 & -0.025 \\
Serious & -0.378 & -0.501 & -0.091 & -0.050 & -0.034 \\
Severe & -0.422 & -0.551 & -0.101 & -0.057 & -0.041 \\
\hline
\end{tabular}

Moreover, spatial differences in channel erosion impact on water level leads to changes in water surface slope. Generally, the water surface elevation decreases from south to north in Poyang Lake and the water head from Kangshang to Hukou can be more than $7 \mathrm{~m}$ during the dry period. Water level declines caused by channel erosion increased gradually from Kangshan, through Longkou to Tangyin, and reached a maximum at Duchang (Table 2). Therefore, the water surface slope increased significantly from Kangshan to Duchang. Under severe channel erosion conditions, the mean water head between Kangshan and Duchang increases by approximately $0.5 \mathrm{~m}$ 
and the maximum increase reaches approximately $1.4 \mathrm{~m}$. However, due to the blocking effect of the Yangtze River, the impact of channel erosion on water levels decreased from Duchang to the north end of the lake. In particular, water level at Hukou are thought to be determined by the Yangtze River (Cai et al., 2015), thus the impact of channel erosion can be neglected. The water surface gradient from Duchang to Hukou declined after channel erosion. The water head decreased by an average of $0.6 \mathrm{~m}$ under severe channel erosion condition.

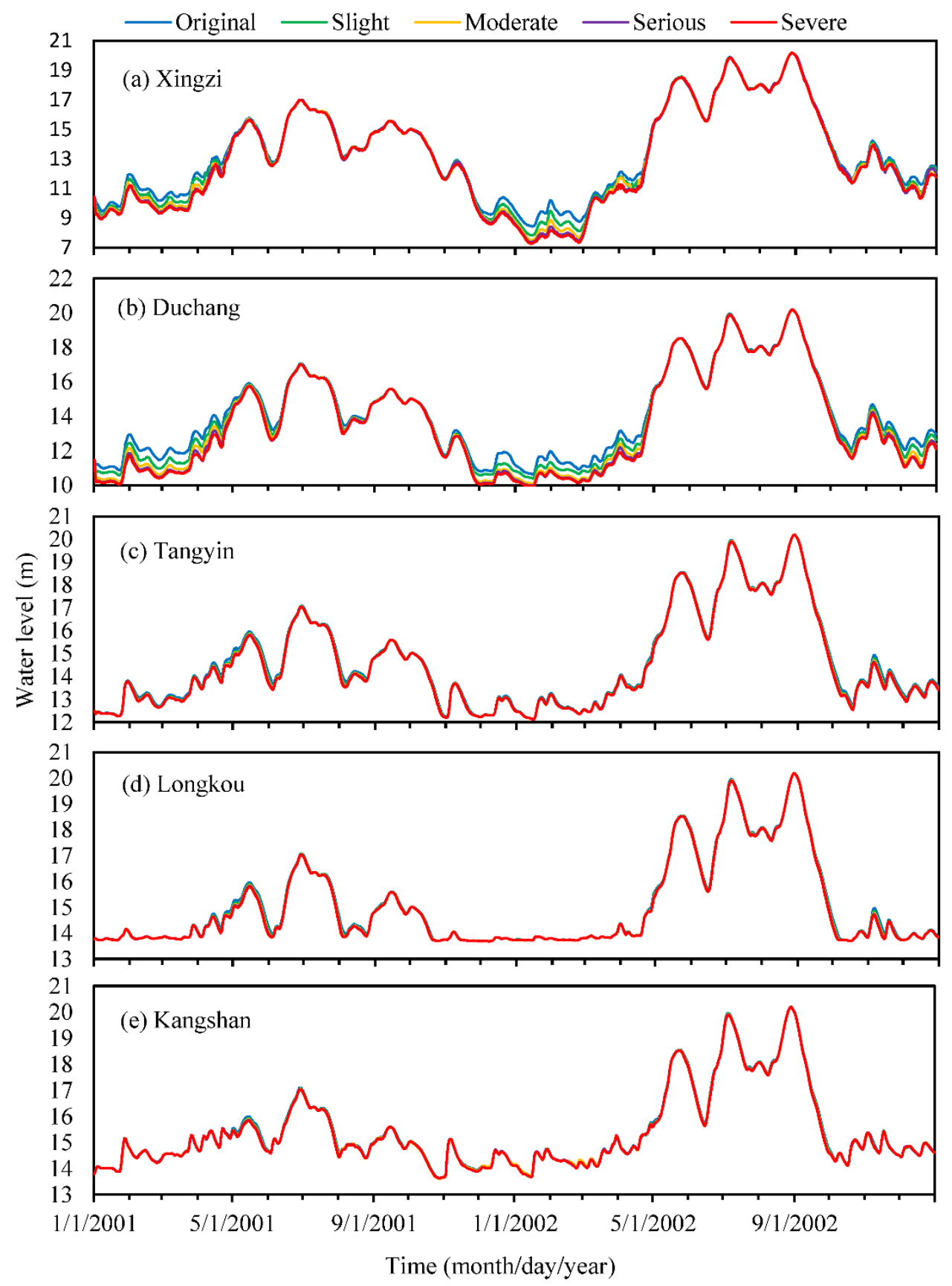

Figure 5. Comparison of the simulated water levels under different channel erosion intensities

(slight, moderate, serious, severe intensity) with the water levels before channel erosion (original) at $\boldsymbol{a}$ Xingzi, $\boldsymbol{b}$ Duchang, $\boldsymbol{c}$ Tangyin, $\boldsymbol{d}$ Longkou, $\boldsymbol{e}$ Kangshan. Water levels at the five gauging stations all decreased after channel erosion 
Furthermore, the decrease in water level at the five stations influenced by channel erosion were not temporally identical. Figure 6 shows the amplitude of decrease in monthly average water levels under severe channel erosion conditions. In general, water levels in the dry period were more sensitive to channel erosion than in the wet period. During the dry period, the water level in the northern channel was most affected. The water levels at Xingzi and Duchang decreased significantly, by an average of $0.90 \mathrm{~m}$ and $1.1 \mathrm{~m}$. Monthly average water levels at Xingzi and Duchang all reduced more than $0.52 \mathrm{~m}$ and $0.70 \mathrm{~m}$, respectively. The maximum daily water level reduction in Xingzi and Duchang station occurred on January 31, 2002, and March 30, 2001, reaching $2.05 \mathrm{~m}$ and $1.37 \mathrm{~m}$, respectively. During the rising and receding water periods, water levels at Xingzi and Duchang decreased an average of $0.40 \mathrm{~m}$ and $0.61 \mathrm{~m}$. Water levels in the central and eastern part of the lake decreased by an average of $0.27 \mathrm{~m}$ and $0.20 \mathrm{~m}$ at Tangyin and Longkou, respectively. The maximum water level reductions at Tangyin and Longkou all occurred in May 2001, reaching $0.46 \mathrm{~m}$, and $0.37 \mathrm{~m}$, respectively. During the wet period, water level changes were all less than $0.1 \mathrm{~m}$.

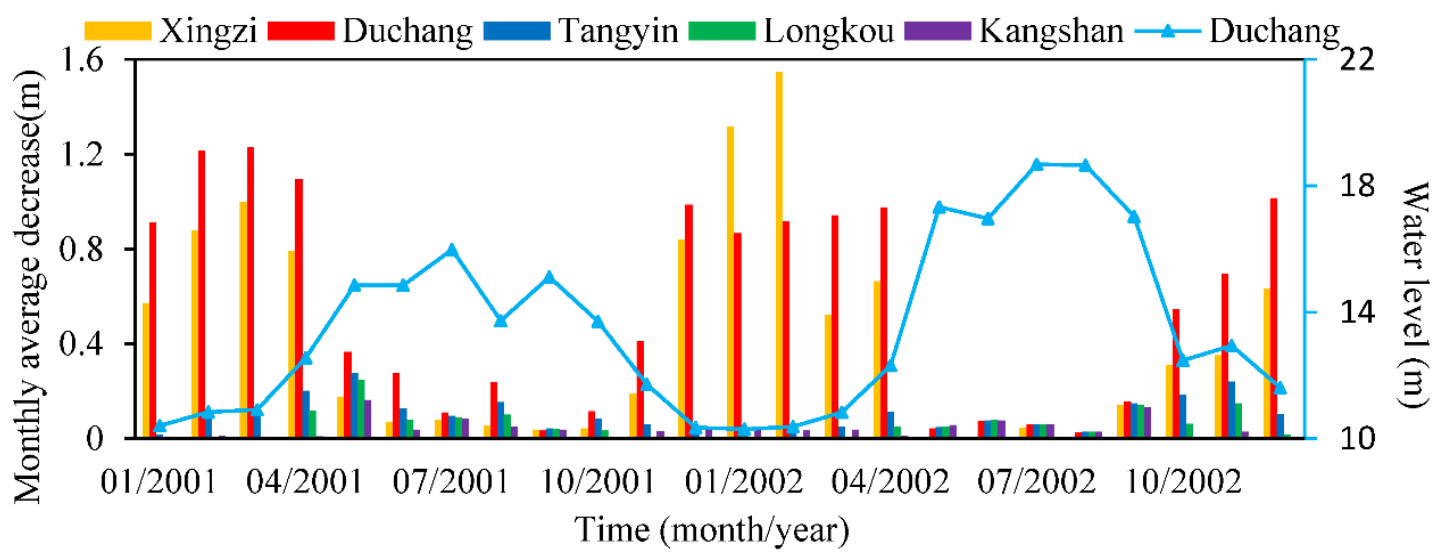

Figure 6. Decrease in monthly average water level (marked as bars) at Xingzi, Duchang, Tangyin, Longkou and Kangshan under severe channel erosion conditions. Decrease of water level caused by channel erosion was more significant in the dry period when water level in the lake (marked as dots with solid line, Duchang) is low

\section{Channel erosion impact on water distribution in the lake}

An additional study was performed on the effect of water distribution in Poyang Lake, which was represented by water depth changes after channel erosion. Figure 7 shows the water depth changes after a severe intensity of erosion during a low water period, rising water period, high water period, and receding water period in 2001. Although water levels in the channel from Duchang to Hukou decreased, the water depth in the channel increased by $2.0 \mathrm{~m}$ to $4.0 \mathrm{~m}$ over the whole year. Similarly, the water depth in the northern branch inflow channel of Ganjiang increased by $0.5 \mathrm{~m}$ to $1.0 \mathrm{~m}$. However, the influence of water depth on the floodplain areas changed in the different periods. During the low water period, the water depth in the floodplain between Xingzi and Duchang decreased by 1.0 to $2.0 \mathrm{~m}$. In addition, the water depth in the middle of the lake decreased by 0.1 to $0.5 \mathrm{~m}$. During the rising water period, the water depth decreased by 0.5 to $1.0 \mathrm{~m}$ in the central lake area, and 0.1 to $0.5 \mathrm{~m}$ in the eastern floodplain. During the high water period, the impact of water depth on the 
floodplain area was negligible. During the receding water period, the water depth decreased by 0.1 to $0.5 \mathrm{~m}$ in the central and eastern part of the lake. Changing water depths in Poyang Lake indicated that channel erosion redistributed water in the lake, namely, water in the middle and eastern floodplain and areas nearby the channel drained to the outflow channel.

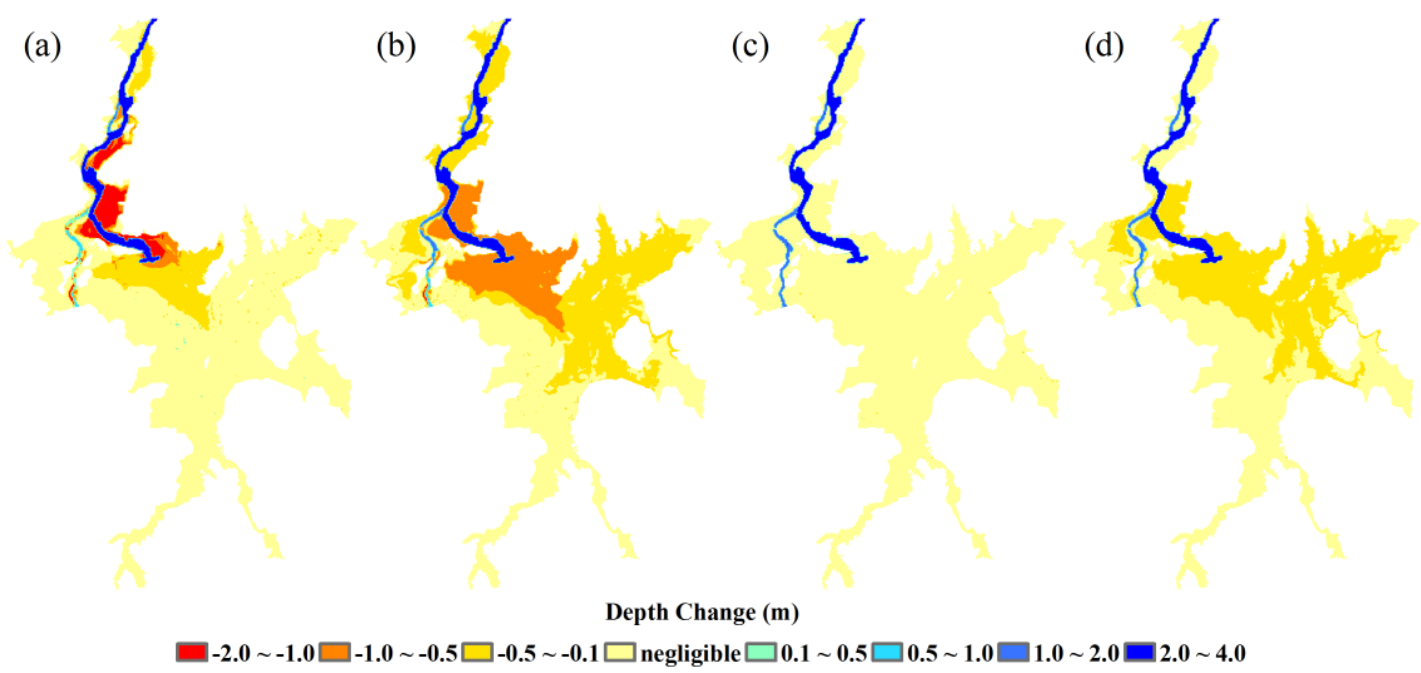

Figure 7. Water depth changes under sever channel erosion conditions on a March 30, 2001, during low water period, b May 30, 2001, during rising water period, $\boldsymbol{c}$ June 29, 2001, during high water period, and $\mathbf{d}$ October 17, 2001, during the receding water period

\section{Impact of channel erosion on lake-river interactions}

Simulated daily discharge at Hukou under different channel erosion intensities were compared with the outflow before channel erosion. The results in Table 3 show that channel erosion increased the total outflow discharge to the Yangtze River from the Poyang Lake slightly during the simulation period. Although the channel's morphological changes influence on the outflow discharge was not as great as the inflow volumes and the outlet water level variations, the temporally heterogeneous influence changed lake-river interactions. The results indicate that outflow discharges increased in the dry period, but tended to decrease in the wet period. The impact on outflow discharge enhanced due to stronger channel erosion intensities. Topographical changes altered the lake volume and hydraulic condition of the lake, thereby changing the lake's discharge ability and regulation capacity. As erosion decreased the bottom elevation, the lake volume in the four scenarios with different intensities of channel erosion increased by $1.3 \times 10^{8} \mathrm{~m}^{3}, 2.6 \times 10^{8} \mathrm{~m}^{3}, 3.9 \times 10^{8} \mathrm{~m}^{3}$, and $5.2 \times 10^{8} \mathrm{~m}^{3}$, respectively. The increasing storage capacity of the lake might decrease the outflow discharge since the lake was able to hold more water. However, variations in the channel bottom topography elevation increased the wetted cross-sectional area and the hydraulic gradient. These two different processes induced a considerable variation in lake-river interaction.

During the dry period, the lake outflow into the Yangtze River increased with channel downcutting depth. During this period, inflow water flow ran through the channel in the lake and drained into the Yangtze River due to the large difference in water level between the southern and the northern part of the lake (an average of $4.5 \mathrm{~m}$ 
from Kangshan to Hukou) and the weak blocking effect of the Yangtze River. Channel erosion increased the wetted cross-sectional area and the hydraulic radius of the lake outflow channel, thus increasing the lake conveyance capacity, which represents the essential discharge ability of an open lake outflow channel (Lai et al., 2014). The results in Figure 8 show that Poyang Lake's outflow channel conveyance capacity increased with different intensities of channel erosion. The average lake conveyance capacity before channel erosion was approximately $2290 \mathrm{~m} .5 / \mathrm{s}$, and for the four channel erosion scenarios in this study it increased by $25.0 \%, 58.7 \%, 99.4 \%$, and $135.8 \%$, respectively. The increasing conveyance capacity implies that water flows more easily from the channel into the Yangtze River. A larger increase in the outflow channel conveyance capacity occurred during the low water period of Hukou. For example it increased by $260 \%$ at a level of $7.2 \mathrm{~m}$, which has the potential to intensify the drought during this period. Moreover, significant decrease in water levels in the northern watercourse caused by channel erosion increased the water surface slope during the dry period, accelerating the water flow into the channel, and increasing the total outflow discharge.

Table 3. Relative change rate of outflow discharge at Hukou station compared to that before channel erosion after slight, moderate, serious, severe intensity of channel erosion

\begin{tabular}{c|c|c|c}
\hline & Dry period & Wet period & All \\
\hline Slight & $0.38 \%$ & $-0.01 \%$ & $0.05 \%$ \\
Moderate & $0.76 \%$ & $-0.06 \%$ & $0.08 \%$ \\
Serious & $1.02 \%$ & $-0.09 \%$ & $0.10 \%$ \\
Severe & $1.20 \%$ & $-0.11 \%$ & $0.11 \%$ \\
\hline
\end{tabular}

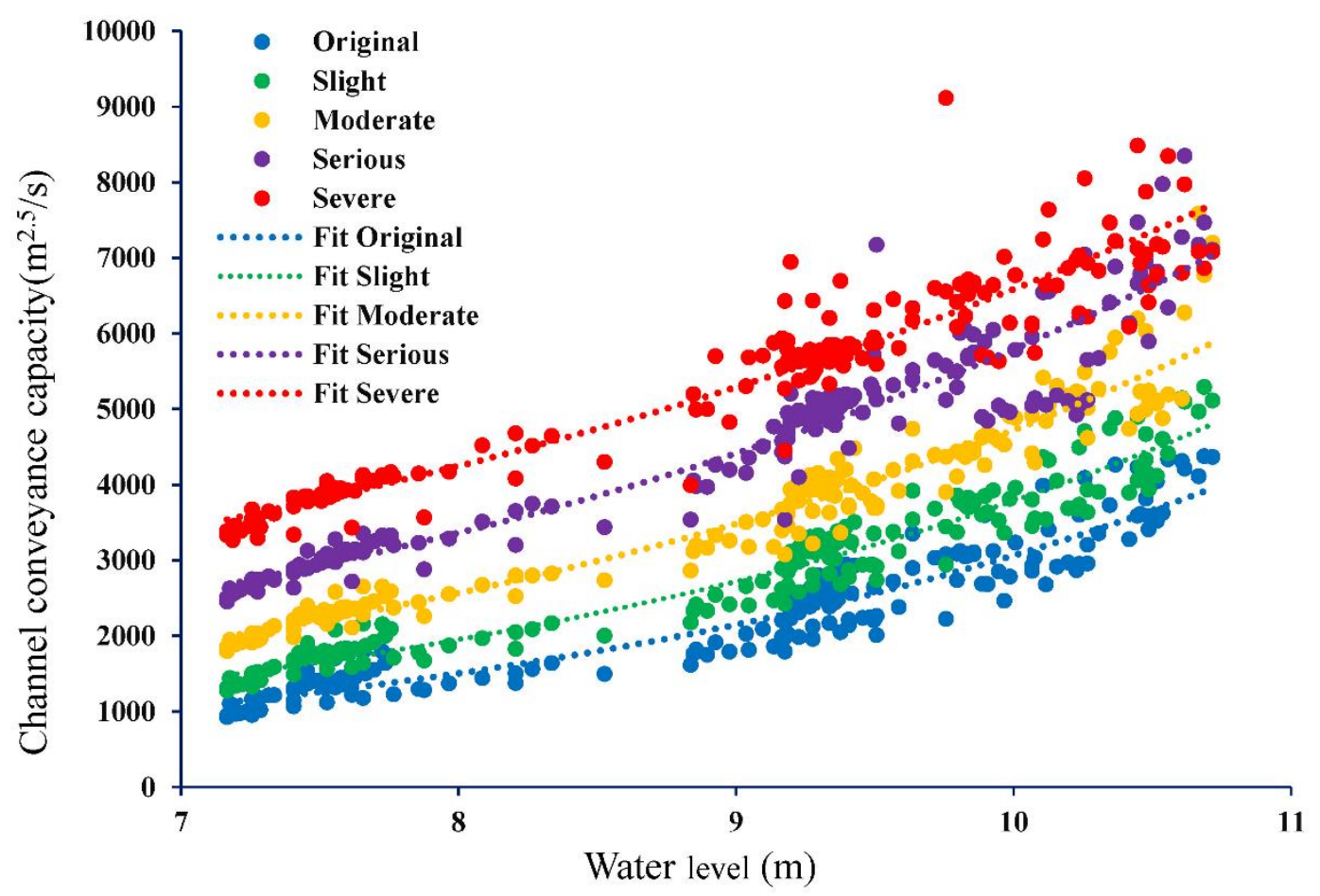

Figure 8. The impact of channel erosion on the relationship between the lake conveyance capacity and Hukou water level during the low water period 
During the wet period, outflow discharge tended to decrease. During this period, the water head between the southern upstream and the northern downstream in Poyang Lake decreased dramatically (an average of $1.0 \mathrm{~m}$ from Kangshan to Hukou). Simultaneously, higher water levels in the Yangtze River significantly enhanced the blocking effect to Poyang Lake outflow. The changing hydraulic conditions and lake volume caused by channel morphological variations altered the regulation process, thereby affecting the river-lake interaction and outflow discharge. A quantitative analysis of the lake's water balance can be expressed as Equation 4:

$$
\Delta V=I-Q
$$

where $\mathrm{Q}$ is the outflow at Hukou, I is the inflow of Poyang Lake, and $\Delta \mathrm{V}$ is the change in lake water storage (positive for volume increase). Figure $9 a$ shows a good-fit linear relationship between the lake volume (V) and water level $(\mathrm{Z})$ during high water period. Therefore, the change in lake water storage can be represented as a curve differential coefficient (Eq. 5).

$$
\Delta V=\Delta f(Z) / \Delta Z
$$

The relationship between lake water storage and water levels before channel erosion and after severe channel erosion is shown in Figure 9b, which indicates that channel erosion altered the lake volume change rate. In the four channel erosion scenarios, the change in lake volume caused by per meter variation in water level at Hukou increased $1.7 \times 10^{7} \mathrm{~m}^{3}, 2.8 \times 10^{7} \mathrm{~m}^{3}, 3.6 \times 10^{7} \mathrm{~m}^{3}$, and $4.1 \times 10^{7} \mathrm{~m}^{3}$, respectively. During the high water period, the lake pondage of inflows (Huang, 2011) increased by $3.8 \times 10^{8} \mathrm{~m}^{3}$, $5.8 \times 10^{8} \mathrm{~m}^{3}, 7.3 \times 10^{8} \mathrm{~m}^{3}$, and $8.2 \times 10^{8} \mathrm{~m}^{3}$, respectively. Thereby, outflow discharge to the Yangtze River decreased.
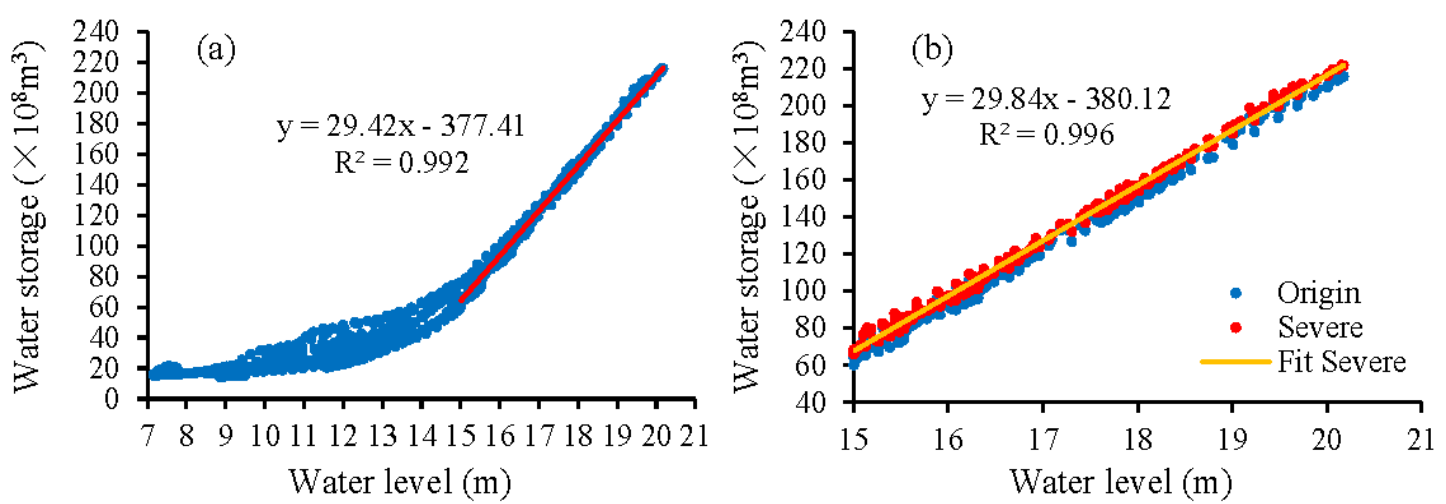

Figure 9. a Relationship between water storage in Poyang Lake and water level at Hukou, and there is a good-fit linear relationship during high water period. $\boldsymbol{b}$ The changing relationship between the lake water storage and Hukou water level under severe channel erosion condition during high water period

Furthermore, a larger storage capacity and lower water levels in the lake theoretically increased the backflow frequency and volume from the Yangtze River towards Poyang Lake (Gao et al., 2014). During the simulation period, backflow occurred from August 
23 to August 26, 2002, and the volume of backflow was approximately $3.2 \times 10^{8} \mathrm{~m}^{3}$. In our four different intensities of channel erosion scenarios, the backflow volume increased to $3.3 \times 10^{8} \mathrm{~m}^{3}, 4.5 \times 10^{8} \mathrm{~m}^{3}, 4.6 \times 10^{8} \mathrm{~m}^{3}$, and $5.1 \times 10^{8} \mathrm{~m}^{3}$, respectively. The backflow occurred 3 days in advance under severe channel erosion conditions. Therefore, channel erosion has a significant influence on the water exchange between the Yangtze River and Poyang Lake.

\section{Changes of wet-dry characteristics}

Poyang Lake shows significant seasonal variations, alternating between wet and dry periods. Using six decades (1952-2011) of observed water level data from Duchang station, the representative hydrological station of Poyang Lake, Min and Zhan (2012) divided the dry period into five low-water level statuses, including a general low-water level $(11.8 \mathrm{~m}<\mathrm{H} \leq 12.8 \mathrm{~m})$, a moderate low-water level $(10.8 \mathrm{~m}<\mathrm{H} \leq 11.8 \mathrm{~m})$, a serious low-water level $(9.8 \mathrm{~m}<\mathrm{H} \leq 10.8 \mathrm{~m})$, a severe low-water level $(8.8 \mathrm{~m}<\mathrm{H} \leq 9.8 \mathrm{~m})$ and an extreme low-water level $(\mathrm{H} \leq 8.8 \mathrm{~m})$. The wet-dry characteristics are closely associated with water supply, irrigation and shipping. During the simulation period, water level at Duchang station varied from $9.90 \mathrm{~m}$ to $20.12 \mathrm{~m}$, encompassing the low-water level status except for severe and extreme low-water level.

Figure 10 shows the alteration of wet and dry periods in Poyang Lake during 2001 and 2002. The results imply that channel downcutting made the dry period start earlier and end later, resulting in a longer dry period and an emergence of lower water levels. As bottom erosion increased the outflow channel conveyance capacity and the hydraulic slope from the channel to the floodplain area, the transitional process from dry to wet slowed down. The date the dry period ended in 2001 and 2002 was delayed 6 to 27 days under different channel erosion intensities. Generally, the time delay increased with the channel erosion depth. The effect in drier years was more significant as less water supply was available to supplement the water loss in the lake. Moreover, the results indicate an earlier arrival of the dry period due to larger bottom slope that accelerated water drainage to the channel. The date the dry period started in 2001 and 2002 advanced 1 to 5 days. The two effects of channel erosion on wet-dry characteristics extended the dry period time in Poyang Lake.

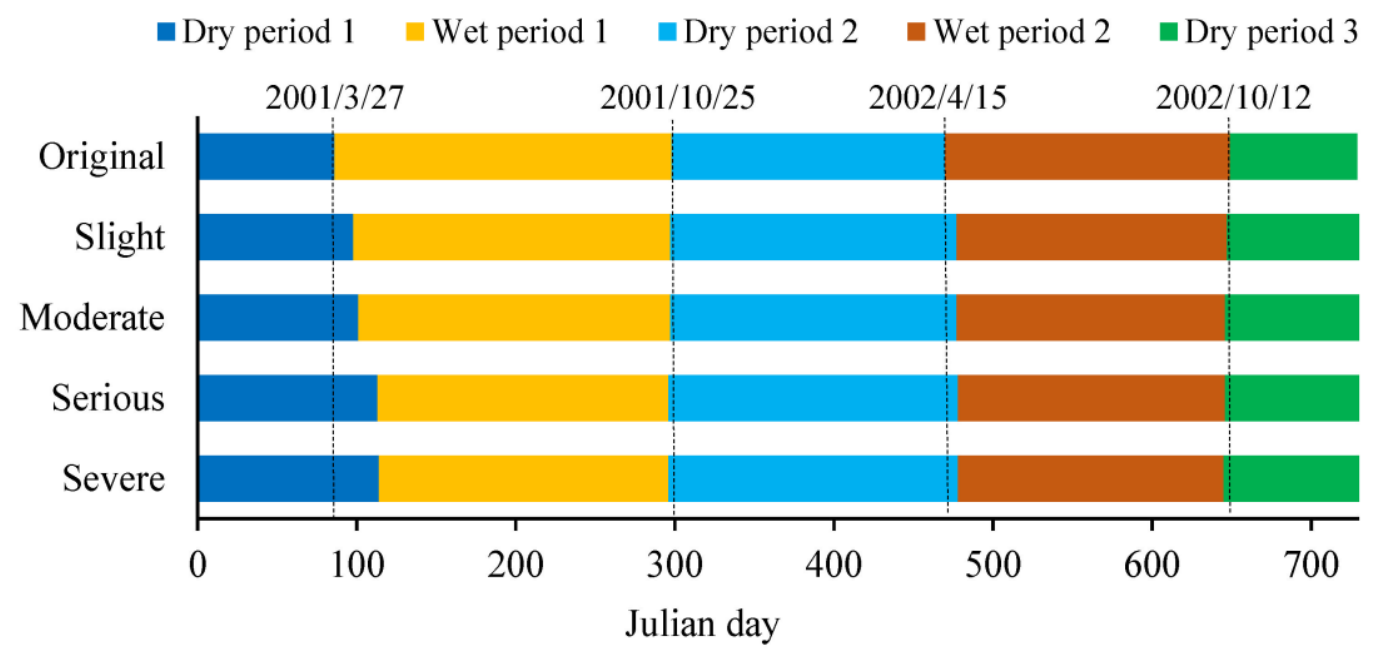

Figure 10. Comparison of the distribution of wet and dry periods in 2001 and 2002 without or under different channel erosion intensities 
Furthermore, days of general low-water level (T1 in Fig. 11), moderate low-water level (T2 in Fig. 11) and serious low-water level (T3 in Fig. 11) displayed on an upward trend with an increase in the channel erosion intensity. Cumulative days of general lowwater level increased $15 \%, 22 \%, 28 \%$, and $32 \%$, respectively under slight, moderate, serious, and severe channel erosion conditions. In addition, moderate low-water level days increased $47 \%, 63 \%, 81 \%$ and $92 \%$, respectively. In particular, days of serious low-water level were 5.2 to 14.6 times that before channel downcutting. The results under severe channel erosion show that the frequency of serious low-water level increased dramatically from 1.5 to $23.6 \%$. Additionally, the lowest water levels over the runtime decreased $0.23 \mathrm{~m}, 0.54 \mathrm{~m}, 0.68 \mathrm{~m}$, and $0.73 \mathrm{~m}$. Extreme low water level may occur as the bottom elevation of the channel decreases.

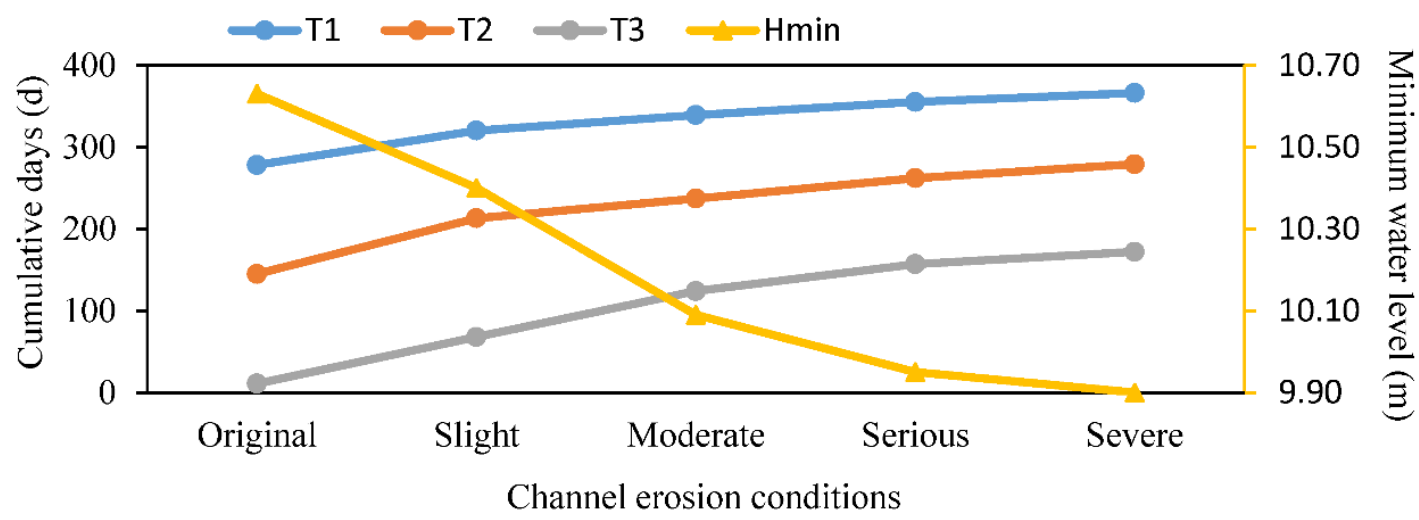

Figure 11. Cumulative days of low-water level and lowest water level under different channel erosion conditions. T1, T2, and T3 represent cumulative days of general low water level, moderate low water level, and serious low water level during the simulation period. $H_{\min }$ is the minimum water level occurred at Duchang station

\section{Discussion}

A long-term examination of lake water levels conducted by Min and Zhan (2012) and trend testing of lake water levels conducted by Zhang et al. (2014) showed that water levels of Poyang Lake were significantly lower during the 2000s. In addition to the influence of variations in Yangtze River water regime, local catchment precipitation, lake inflow runoff (Hu et al., 2007; Zhang et al., 2012; Feng et al., 2012b; Liu et al., 2013), the changes in bottom topography were identified as one of the influential factors (Lai et al., 2014; Yao et al., 2018). Our study further investigated the spatiotemporal impact of channel erosion on the hydrological and hydrodynamic characteristics. The results of this work agreed with the previous studies, which suggested that decreases in channel elevation lead to lower water levels in the lake during the dry period. An assessment of the lake water level variations indicated significant spatiotemporal heterogeneity in channel erosion impact. Water surface elevation during the dry period near the channel decreased most and water levels in the middle of the lake near Duchang and the floodplain area in the eastern and southern part of the lake were evidently affected. In contrast, water levels during the wet period were almost unaffected. Thus the influences of topography changes on specific low-water regimes in the lake needs further evaluation combined with the spatiotemporal characteristics of the events. The results from the simulation of different channel erosion intensities 
showed that the reduction of water levels increased with the downcutting depth of the watercourse. Lower water levels, especially during the dry period, potentially caused great water intake difficulties for industry, agriculture and living organisms. With the influence of both climate changes and human activities, dramatic changes in water regime and hydro-environment have occurred in many shallow waters (Ma et al., 2010; Feng et al., 2012; Gosling et al., 2016; Lu et al., 2019; Zhou et al., 2019). Topography changes were often ignored in water balance analysis, as much effort was expended on the changes of inflow volume and outflow boundary conditions. However, topography changes can also induced significant variations in hydrological and hydrodynamic processes. Thus consideration of topography changes and their impacts promote understanding of the water regime fluctuation and assist management of water resources.

Erosion in the outflow channel influenced water exchanges between the Yangtze River and Poyang Lake. The results in this study suggest that outflow discharge during the dry period was larger after channel erosion, which agreed with the analysis of Lai et al. (2014). The increase in outflow discharge from Poyang Lake enhanced the emptying effects (Zhang et al., 2012), which may lead to a drier lake environment. Moreover, larger outflow discharge increased the sediment load from the lake, which in turn decreased the bottom of the lake basin. Gao (2014) investigated the sand budget between Poyang Lake and Yangtze River and stressed that sediment load from the lake over the low-water period increased by 10.08 Mt during the 2003-2010 owing the outflow discharge increase. Our study further analyzed the impact of channel erosion on lake-river interactions during the high water period, which was not considered in previous studies. The results indicated that channel erosion increased the regulation capacity of Poyang Lake during the wet period, therefore increasing the pondage volume of inflows. The increase in regulation capacity of Poyang Lake reduced outflow discharges into the Yangtze River during the flooding period and it reduced the flood pressure of downstream. In addition, channel erosion facilitated backflow from the Yangtze River to Poyang Lake. The increase of backflow frequency and volume altered the exchange of suspended sediments and nutrients between Poyang Lake and the Yangtze River, which further affected ecological processes. Cui (2009) estimated the spatiotemporal effects of backflow on the water clarity in Poyang Lake by satellite images. As the river water contains a higher concentration of sediment, the increase of backflow would result in decline of water clarity in the northern and central lake. The changing lake-river interaction has a vitally important influence on water regimes in Poyang Lake, as well as the hydro-environment.

Further studies on changes of the wet-dry characteristics indicated that channel erosion may have a substantial influence on vegetation and ecosystems. An extension of the dry period would affect vegetation growth since water is a critical factor for vegetation growth. Moreover, as the water demand for growth varies for different vegetation, changes in the growth environment may also alter the competitive advantage of different species, causing related ecological and environmental problems. Wu (2017) found that the early arrival of dry period caused the expanding of Phalaris to mudflat zone in Poyang Lake after 2000. Longer duration and lower water levels of the dry period resulted in sharp decrease of lake grass land and increase of woodland and reed (Yang et al., 2016). Additionally, long dry periods are not beneficial to water selfpurification, and increases the risk of water pollution. Ni (2015) examined the effects of hydrological conditions on organic phosphorus and found that the prolonged dry period 
caused a longer exposed time of sediments and resulted in a higher concentration of organic phosphorus. Therefore, variations in hydrological and hydrodynamic processes induced by topography changes deserve attention for maintaining reasonable conditions for the hydro-environment.

\section{Conclusions}

This study assessed the spatiotemporal impacts induced by topography changes, specifically channel erosion, on hydrological and hydrodynamic characteristics in China's largest freshwater lake, Poyang Lake. A hydrodynamic model was used to simulate hydrodynamic processes under different erosion intensities. The spatiotemporal impacts of channel erosion on water levels, water distribution, lake-river interactions, and wet-dry characteristics were assessed. The results show that channel erosion induced variations in hydrological and hydrodynamic characteristics in Poyang Lake with spatiotemporal heterogeneity. The channel erosion caused lower water levels in the lake, and the reduction in water level was enhanced due to stronger erosion intensity. The decrease in water level was significant during the dry period, whereas it was negligible during the wet period. The topographical changes affected water levels the most in the northern channel with an average water level decrease of $0.9-1.1 \mathrm{~m}$ during the dry period. Water levels in the central and eastern part of the lake decreased by an average of $0.27 \mathrm{~m}$ and $0.20 \mathrm{~m}$, respectively, during the rising water and receding water period. In contrast, the water level decreased an average of $\leq 0.1 \mathrm{~m}$ in the southern lake. Moreover, the water surface slope changed and further influenced the distribution of water by gathering water to the channel from nearby floodplain areas. Furthermore, the topographic changes affected the exchange of water between Poyang Lake and the Yangtze River, as well as interactions between Poyang Lake and inflow tributaries. During the dry period, the channel conveyance capacity increased by 25$136 \%$, resulting in a larger outflow discharge into the Yangtze River. In contrast, during the wet period, the regulation capacity increased the pondage volume of inflows by 3.8$8.2 \times 10^{8} \mathrm{~m}^{3}$, decreasing outflow discharges. In particular, the backflow frequency and volume from the Yangtze River to Poyang Lake increased after channel erosion during the flooding period of the Yangtze River. Additionally, the hydrological and hydrodynamic changes increased the duration of the dry period of Poyang Lake and significantly increased the frequency of the low water regime events. The decreased minimum water level in the lake indicated that Poyang Lake faced more serious drought conditions after channel erosion.

Results in this study indicate that topographic changes have substantial impacts on flow patterns and material transportation in shallow waters such as Poyang Lake. Hydrological and hydrodynamic changes, resulting in water shortage and ecological problems in shallow water, are not only associated with inflow water regime and outflow conditions, but also significantly influenced by topographic changes. Bathymetry monitoring would provide fundamental data for assessment of topographic variations caused by natural factors and human activities, which supports further studies on the hydrological and environmental impacts induced by topography changes. Extensive sand mining is a critical cause of channel erosion in Poyang Lake. The lower water level and extended dry period, in turn, aggravates scour of the channel bottom. Thus, supervision of human activities such as sand dredging in the lake is necessary. The numerical simulation method provided in this study to analyze hydrological and 
hydrodynamic changes can be extended to other rivers or lake basins, where significant topographic changes such as erosion and deposition occur. Further study should investigate the impacts of topography changes on water quality and eco-hydrological environment, coupling the water quality models and ecological models. Reproduction and prediction with numeric models can inform quantitative assessment of the impacts of topography deformation, supporting analysis of water resource and management decisions of the watershed.

Acknowledgements. This work was funded by the National Key Research and Development Program (2017YFB0504103), the National Natural Science Funding of China (NSFC) (41331174), the Open Foundation of Jiangxi Engineering Research Center of Water Engineering Safety and Resources Efficient Utilization (OF201601), the Fundamental Research Funds for the Central Universities (2042018kf0220) and the LIESMARS Special Research Funding. We would thank the Delft Hydro-Morphodynamics for providing open source code of Delft3D-Flow.

\section{REFERENCES}

[1] Cai, X., Gan, W., Ji, W., Zhao, X., Wang, X., Chen, X. (2017): Optimizing remote sensing-based level-area modeling of large lake wetlands: case study of Poyang Lake. IEEE Journal of Selected Topics in Applied Earth Observations and Remote Sensing 8(2): 471-479.

[2] Cui, L., Wu, G., Liu, Y. (2009): Monitoring the impact of backflow and dredging on water clarity using MODIS images of Poyang Lake, China. - Hydrological Processes 23(2): 342-350.

[3] Delft Hydraulics (2014): Delft3d-Flow User Manual: Simulation of Multi-Dimensional Hydrodynamic Flows and Transport Phenomena, Including Sediments. - Deltares, Delft, The Netherlands, pp.1-683.

[4] Feng, L., Hu, C., Chen, X., Li, R., Tian, L., Murch, B. (2011): MODIS observations of the bottom topography and its inter-annual variability of Poyang Lake. - Remote Sensing of Environment 115(10): 2729-2741.

[5] Feng, L., Hu, C., Chen, X., Cai, X., Tian, L., Gan, W. (2012a): Assessment of inundation changes of Poyang Lake using MODIS observations between 2000 and 2010. - Remote Sensing of Environment 121(2): 80-92.

[6] Feng, L., Hu, C., Chen, X. (2012b): Satellites capture the drought severity around China's largest freshwater lake. - IEEE Journal of Selected Topics in Applied Earth Observations and Remote Sensing 5(4): 1266-1271.

[7] Gao, J., Jia, J., Kettner, A. J., Xing, F., Wang, Y. P., Xu, X. N., Yang, Y., Zou, X., Gao, S., Qi, S., Liao, F. (2014): Changes in water and sediment exchange between the Changjiang River and Poyang Lake under natural and anthropogenic conditions, China. Science of the Total Environment 481(1): 542-553.

[8] Gosling, S. N., Arnell, N. W. (2016): A global assessment of the impact of climate change on water scarcity. - Climate Change 134: 371-385.

[9] Hu, Q., Feng, S., Guo, H., Chen, G., Jiang, T. (2007): Interactions of the Yangtze River flow and hydrologic processes of the Poyang Lake, China. - Journal of Hydrology 347(1): 90-100.

[10] Huang, S. Y. (2011): Research on Poyang Lake's pondage action under extreme flood encountering. - Master Thesis, Nanjing University, Nanjing.

[11] Lai, X., Jiang, J., Huang, Q., Xu, L. (2011): Two-dimensional numerical simulation of hydrodynamic and pollutant transport for lake Poyang. - Journal of Lake Science 23(6): 893-902. 
[12] Lai, X., Shankmanm, D., Huber, C., Yesou, H., Huang, Q., Jiang, J. (2014): Sand mining and increasing Poyang Lake's discharge ability: a reassessment of causes for lake decline in China. - Journal of Hydrology 519: 1698-1706.

[13] Leeuw, J. D., Shankman, D., Wu, G., Boer, W. F., Burnham, J., He, Q., Yesou, H., Xiao, J. (2010): Strategic assessment of the magnitude and impacts of sand mining in Poyang Lake, China. - Regional Environmental Change 10(2): 95-102.

[14] Li, H., Chen, X., Lu, J., Zhang, P., Qi, H. D., Chen, L. (2016): Numerical simulation of suspended sediment concentration in Lake Poyang during flood season considering dredging activities. - Journal of Lake Science 28(2): 421-431.

[15] Li, J., Tian, L., Chen, X., Li, X., Huang, J., Lu, J., Feng, L. (2014): Remote-sensing monitoring for spatiotemporal dynamics of sand dredging activities at Poyang Lake in China. - International Journal of Remote Sensing 35(16): 6004-6022.

[16] Li, Y., Zhang, Q., Yao, J., Werner, A. D., Li, X. (2014): Hydrodynamic and Hydrological modeling of Poyang Lake catchment system in China. - Journal of Hydrologic Engineering 19(3): 607-616.

[17] Liu, Y., Wu, G., Zhao, X. (2013): Recent declines in China's largest freshwater lake: trend or regime shift? - Environmental Research Letters 8(1): 14010-14019.

[18] Lu, J., Zhang, L., Cui, X., Zhang, P., Chen, X., Sauvage, S., Sanchez, J. M. (2019): Assessing the climate forecast system reanalysis weather data driven hydrological model for the Yangtze River Basin in China. - Applied Ecology and Environmental Research 17: 3615-3632.

[19] Ma, R., Duan, H., Hu, C., Feng, X., Li, A., Ju, W., Jiang, J., Yang, G. (2010): A halfcentury of changes in China's lakes: Global warming or human influence? - Geophysical Research Letters 37: L24106.

[20] Malhadas, M. S., Silva, A., Leitao, P. C., Neves, R. (2009): Effect of the bathymetric changes on the hydrodynamic and residence time in Obidos Lagoon (Portugal). - Journal of Coastal Research 2009: 549-553.

[21] Min, Q. (2000): Changes of morphology and water regime in Poyang Lake over the recent 50 years and its relation to reclamation. - Advances in Water Science 11(1): 76-81.

[22] Min, Q., Zhan, L. (2012): Characteristics of low-water level changes in Lake Poyang during 1952-2011. - Journal of Lake Science 24(5): 675-678.

[23] Moriasi, D. N., Arnold, J. G., Van Liew, M. W., Bingner, R. L., Harmel, R. D., Veith, T. L. (2007): Model evaluation guidelines for systematic quantification of accuracy in watershed simulations. - Transactions of the Asabe 50(3): 885-900.

[24] Mosley, L. M. (2015): Drought impacts on the water quality of freshwater systems, review and integration. - Earth-Science Reviews 140(3): 203-214.

[25] Ni, Z., Wang, S., Zhnag, L., Wu, Z. (2015): Role of hydrological conditions on organic phosphorus forms and their availability in sediments from Poyang Lake, China. Environmental Science and Pollution Research 22: 10116-10129.

[26] Oliveira, A., Fortunato, A., Rego, J. (2006): Effect of morphological changes on the hydrodynamics and flushing properties of the Obidos lagoon (Portugal). - Continental Shelf Research 26: 917-942.

[27] Qi, H., Lu, J., Chen, X., Sauvage, S., Sanchez-Pérez, J. M. (2016): Water age prediction and its potential impacts on water quality using a hydrodynamic model for Poyang Lake, China. - Environmental Science and Pollution Research 23(13): 13327-13341.

[28] Qi, S., Zhang, X., Wang, D., Zhu, J., Fang, C. (2014): Study on morphologic change in Poyang Lake basin caused by sand dredging using multi-temporal Landsat images and DEMs. - The International Archives of the Photogrammetry, Remote Sensing and Spatial Information Science, Volume XL-1, 2014. ISPRS Technical Commission I Symposium, 17-20 November 2014, Denver, Colorado, USA.

[29] Rinaldi, M., Mengoni, B., Luppo, L., Darby, S. E., Mosselman, E. (2008): Numerical simulation of hydrodynamics and bank erosion in a river bend. - Water Resource Research 44: W09428. 
[30] Wu, G., Liu, Y., Fan, X. (2015): Bottom topography change patterns of the Lake Poyang and their influence mechanisms in recent 30 years. - Journal of Lake Science 27(6): $1168-1176$.

[31] Wu, H., Zeng, G., Liang, J., Chen, J., Xu, J., Dai, J., Sang, L., Li, X., Ye, S. (2017): Response of landscapr pattern of China's two largest freshwater lakes to early dry season after the impoundment of Three-Gorges Dam. - International Journal of Applied Earth Observation and Geoinformation 56(2017): 36-43.

[32] Yang, G., Zhang, Q., Wan, R., Lai, X., Jiang, X., Li, L., Dai, H., Lei, G., Chen, J., Lu, Y. (2016): Lake hydrology, water quality and ecology impacts of altered river-lake interactions: advances in research on the middle Yangtze River. - Hydrology Research 47(S1): 1-7.

[33] Yang, S., Zhang, J., Dai, S., Li, M., Xu, X. J. (2007): Effect of deposition and erosion within the main river channel and large lakes on sediment delivery to the estuary of the Yangtze River. - Journal of Geophysical Research Earth Surface 112: F022005.

[34] Yao, J., Zhang, Q., Ye, X., Zhang, D., Bai, P. (2018): Quantifying the impact of bathymetric changes on the hydrological regimes in a large floodplain lake: Poyang Lake. - Journal of Hydrology 561: 711-723.

[35] Zhang, L., Lu, J., Chen, X., Liang, D., Fu, X., Sauvage, S., Perz, J. S. (2017): Stream flow simulation and verification in ungauged zones by coupling hydrological hydrodynamic models: a case study of the Poyang Lake ungauged zone. - Hydrology and Earth System Science 21(11): 5847-5861.

[36] Zhang, P., Lu, J., Feng, L., Chen, X., Zhang, L., Xiao, X., Zhang, L., Xiao, X., Liu, H. (2015): Hydrodynamic and inundation modeling of China's largest freshwater lake aided by remote sensing data. - Remote Sensing 7(4): 4858-4879.

[37] Zhang, Q., Li, Y., Wang, Y., Werner, A. D., Xin, P., Jiang, T., Barry, D. A. (2012): Has the three-gorges dam made the Poyang Lake wetlands wetter and drier? - Geophysical Research Letters 39: L20402.1-L20402.7.

[38] Zhang, Q., Ye, X., Werner, A. D., Li, Y., Yao, J., Li, X., Xu, C. (2014): An investigation of enhanced recessions in Poyang Lake: comparison of Yangtze River and local catchment impacts. - Journal of Hydrology 517: 425-434.

[39] Zhou, C. W., Yang, R., Yu, L. F., Zhang, Y., Yan, L. B. (2019): Hydrological and ecological effects of climate change in Caohai watershed based on SWAT model. Applied Ecology and Environmental Research 17: 161-172. 